\title{
Qualitative Analysis of Two Phenolic isomers of Carvacrol and Thymol by using Briggs-Rauscher Oscillator System
}

\author{
Rooh Ullah ${ }^{1, *}$, Saif Ullah ${ }^{1}$, Rasha M.K. Mohamed ${ }^{2, *}$, Muhammad Sufaid Khan ${ }^{3}$, Rozina Khattak ${ }^{4}$, \\ Attiq Ur Rehman Kakar ${ }^{5}$ \\ ${ }^{1}$ Department of Natural and Basic Science, University of Turbat KECH Balochistan Pakistan \\ ${ }^{2}$ Department of Chemistry, College of Science, Jouf University, P.O.Box: 2014, Sakaka, Saudi Arabia \\ ${ }^{3}$ Department of Chemistry, University of Malakand, Chakdara Dir Lower, KPK, 18800, Pakistan \\ ${ }^{4}$ Department of Chemistry, Shaheed Benazir Bhutto Women University, Peshawar, Pakistan \\ ${ }^{5}$ Department of Chemistry, University Balochistan, Balochistan, Pakistan \\ *E-mail: roohullah@uot.edu.pk, rasha_kamal99@yahoo.com
}

Received: 7 September 2021 / Accepted: 18 October 2021 / Published: 10 November 2021

\begin{abstract}
A new technique for identification of two phenolic isomers between carvacrol and thymol was discussed by using their different perturbation effect on Briggs-Rauscher oscillation system. In such system, a macrocyclic complex of $[\mathrm{NiL}]\left(\mathrm{ClO}_{4}\right)_{2}$ was used as catalyst, which ligand $\mathrm{L}$ is $5,7,7,12,14,14$ hexamethyl-1,4,8,11-tetraazacyclotetradeca-4,11-diene. Experimental results proved that the perturbation of equal amount of same concentration two isomers separately into B-R system could temporarily quench the oscillation for period of time prior and regeneration of oscillation. The inhibition is directly proportional to the concentration of isomers. The carvocrol causes inhibition time, while no effect of thymol on the active B-R oscillation is measured. We identified the two phenolic isomers in the range from $1.25 \times 10^{-6}$ to $3.23 \times 10^{-5} \mathrm{~mol} / \mathrm{L}$, and correlation coefficient is 0.98755 . The FCA mechanism based on $\mathrm{HOO}^{\bullet}$ radical has been proposed.
\end{abstract}

Keywords: Phenolic Isomers; Briggs-Rauscher; Perturbation; Inhibitory effect; FCA mechanism

\section{FULL TEXT}

(C) 2021 The Authors. Published by ESG (www.electrochemsci.org). This article is an open access article distributed under the terms and conditions of the Creative Commons Attribution license (http://creativecommons.org/licenses/by/4.0/). 